\title{
THE CHARGE CARRIER CAPTURE-EMISSION PROCESS - THE MAIN SOURCE OF THE LOW-FREQUENCY NOISE IN HOMOGENEOUS SEMICONDUCTORS
}

\author{
V. Palenskis \\ National Center for Physical Sciences and Technology, Faculty of Physics, Vilnius University, Sauletekio 3, LT-10222 Vilnius, Lithuania \\ E-mail: vilius.palenskis@ff.vu.lt
}

Received 10 June 2016; revised 22 July 2016; accepted 23 September 2016

\begin{abstract}
The possibility of determination of the number of localized capture centers of defects (relaxators) that cause low-frequency noise in a particular frequency range has been investigated. Here it is shown that a minimum number of relaxators is needed to generate $1 / \mathrm{f}$ type low-frequency noise only when relaxation times are arbitrarily distributed one-by-one in every two-octave range. The expression for estimation of the low-frequency noise level of the sample under test is presented. The presented expression for $1 /$ f noise explains not only the noise level dependence both on the frequency and number of defects in the sample but also the observed noise intensity dependence on the mobility of free charge carriers. It is shown that the main source that causes low-frequency noise in homogeneous semiconductors is the charge carrier capture-emission process.
\end{abstract}

Keywords: low-frequency noise, capture and emission of charge carriers, defects, RTS, Lorentzian spectrum

PACS: 05.40.Ca, 07.50.Hp, 71.55.-i, 72.70+m

\section{Introduction}

The problem of $1 / f$ noise in various electronic devices has been discussed over 80 years, and over 60 years in solid materials, but the origin of $1 / f$ noise in various materials is still open to discussion. In Ref. [1]], it was stated that the $1 / f$ noise and the $1 / \Delta f[1-3]$ noise have the same physical origin: they are caused by resistance fluctuations. The correlation between $1 / f$ noise and $1 / \Delta f$ noise measurements show the complete correlation giving the direct confirmation that such noises are due to resistance fluctuations [2, 3]. It was directly shown by the measurement of thermal noise modulation that the $1 / f$ noise in homogeneous materials is due to its resistance $R$ fluctuations $\Delta R(t)$ at equilibrium conditions [ [4]. In Ref. [3], it has been shown that the level of $1 / f$ noise does not depend on the additional alternative current power, and the level of $1 / \Delta f$ noise does not depend on the additional direct current power if the sample is not heated; in Ref. [3], it has also been shown that the $1 / f$ noise in nonlinear elements (diodes or transistors) is due to the fluctuations of transfer transconductance. The problem of spectral density of the resistance fluctuation dependence on frequency has been discussed for various materials in many works [5-18]. There are two main opposite points on the origin of $1 / f$ noise: (i) the observed $1 / f$ noise is due to the generation-recombination noise or due to the charge carrier capture and emission in traps of defects [ [8, 10, 12-14, 17, 19]; (ii) the observed $1 / f$ noise is caused by fluctuations in the mobility of free carriers in conducting material $[5,6,15,21-24]$ due to charge carrier lattice scattering. Though the $1 / f$ noise level $\alpha_{\text {meas }}$ in many semiconductor materials can be approximately described by the relation $[15,21-23$.

$$
\alpha_{\text {meas }}=\left(\frac{\mu_{\text {meas }}}{\mu_{\text {latt }}}\right)^{2} \alpha_{\text {latt }},
$$

where $\mu_{\text {meas }}$ is the measured free charge carrier mobility, and $\mu_{\text {latt }}$ is the mobility component due to lattice scattering with $\alpha_{\text {latt }}$ of the order $10^{-4}$, it does not imply that the proportionality of noise intensity to $\mu_{\text {meas }}^{2}$ means that the origin of low frequency is caused by 
mobility fluctuations of free charges. Thus, upholders of mobility fluctuations on the basis of Eq. (1) confirm that the $1 / f$ noise observed in good homogeneous semiconductor samples is due to mobility fluctuations caused by lattice scattering $[15,20-24$. The main argument against the mobility low-frequency fluctuations of free charge carriers is that there is no reliable explanation of the noise spectrum. It is believed that the $1 / f$ noise is caused by fluctuations in the scattering cross-section due to the action of acoustic lattice waves [25, 26]. Considering that the acoustic phonon lifetime in silicon is very short [27] (an average lifetime of thermal acoustic phonons is about $17 \mathrm{ps}$, and according to Ref. [28] the lifetime of acoustic phonons is in the range from $4.7 \mathrm{~ns}$ to $5 \mathrm{ps}$ ), they cannot cause the low-frequency noise. It seems that the nature of both resistance and acoustic phonon intensity fluctuations is the same. If the acoustic phonons would modulate the charge carrier mobility, then the correlation length must be at least about the wavelength of low-frequency acoustic phonons, but experiments show that the correlation length for the $1 / f$ noise is smaller than $1 \mu \mathrm{m}$ [29].

\section{Analysis of the possibility of mobility fluctuations of free charge carriers problem}

Usually in order to explain the conductivity fluctuations of homogeneous material the conductivity $\sigma$ and its fluctuations due to both charge carrier density $n$ and their mobility $\mu$ fluctuations are presented in the following way:

$$
\begin{aligned}
& \sigma=e n \mu, \\
& \Delta \sigma(t)=e \mu \Delta n(t)+e n \Delta \mu(t) .
\end{aligned}
$$

As directly shown in Ref. [4], the low frequency conductivity fluctuations arise in thermal equilibrium conditions. Let us consider what low-frequency (long-time) electronic processes can appear in the thermal equilibrium in the investigated sample. A large number of investigations on random telegraph signals (RTS) and generation-recombination processes show that in the equilibrium free charge carriers take part in the capture-emission process in the localized states of different defects in the sample volume and on its surface. Of course, this charge carrier retrapping process causes the long-time free charge carrier number fluctuations $\Delta n(t)$, and this process is additive. The relaxation time distribution covers a very wide time interval from less than $1 \mu \mathrm{s}$ to more than $1 \mathrm{~s}[12]$. As also shown in [30, 31], the relaxation times of the generation-recombination process for silicon single crystals are distributed in the time interval from 0.1 to $10^{-5} \mathrm{~s}$. The charge carrier capture-emission process is thermally activated and does not change the charge neutrality condition in the sample. The fluctuations of the number of charge carriers could be simply recalculated to the spectral density of sample resistance (or conductance) fluctuations [32].

The question of the mobility fluctuations of free charge carriers is more complicated. It is well known that the mobility in the thermal equilibrium is determined by the average relaxation time $\tau_{\mathrm{r}}$ due to different scattering processes of free charge carriers,

$$
\tau_{\mathrm{r}}=1 /\left(\frac{1}{\tau_{\text {latt }}}+\frac{1}{\tau_{\text {imp }}}\right),
$$

where $\tau_{\text {latt }}$ and $\tau_{\text {imp }}$ are average relaxation times due to lattice and various impurity scattering, respectively. From Eq. (4) it follows that $\tau_{\mathrm{r}}$ is always smaller than any relaxation time component due to any scattering process. For example, the relaxation time for silicon does not exceed $2 \cdot 10^{-13} \mathrm{~s}$ at room temperature [33, 34. The same can be said about the relaxation time of the scattering cross-section. In the case when there is no charge carrier capture-emission process, there cannot be any mobility long-time modulation, because it is determined by the statistical average relaxation time (constant). The average parameters in the equilibrium do not fluctuate. Thus, at the thermal equilibrium the scattering processes cannot be an initial origin of the low frequency noise in materials. In the equilibrium, besides the charge carrier captureemission process, there can be migration of atoms and vacancies, but the latter processes are very weak at room and lower temperatures, and usually have no influence. Now let us see what will happen with mobility fluctuations in the case of the free charge carrier capture-emission process in the localized states of defects. The number of filled and empty localized states changes during the retrapping process, i. e. it changes the number of ionized and neutral defects. As mentioned, the relaxation time of the retrapping process is larger by many orders than that of the free charge scattering process. Thus, the retrapping process can be considered as a quasi-stationary process compared with the charge carrier scattering process. The fluctuations of the number of ionized and neutral defects can in a certain degree induce the changes of the average relaxation time for different scattering mechanisms. This process is not an additive one, contary to the case of charge carrier number fluctuations. The charge carrier capture-emission process in a complex way can change the resultant relaxation 
time and mobility, depending on the material structure, doping density and density of defects, impurities and vacancies, also depending on the temperature and pressure. So, there is a very complex situation how mobility can fluctuate due to the charge carrier capture-emission process, but mobility can never be an initial source for the low-frequency noise, and Eq. (1) does not mean that lattice scattering is the initial origin of the $1 / f$ noise.

In conclusion, it can be pointed that the charge carrier capture-emission process modulates not only the total number of free charge carriers, but in a certain degree can modulate both their average relaxation time and mobility. These modulation phenomena induce both the fluctuations of the power density of thermal noise and low-frequency noise.

\section{What is the cause that the $1 / f$ noise level in semiconductors is often proportional to the squared mobility of free charge carriers?}

In this section the results of resistance fluctuations will be presented on the basis of silicon material due to charge carrier number changes caused by the free charge carrier capture-emission process, and it will be shown that the low-frequency noise level proportionality to the squared mobility for semiconductors is caused by the charge carrier capture-emission process due to mobility decreasing with charge carrier density increasing by doping.

The resistance fluctuation spectral density due to the capture-emission process in $M$ independent capture centers (relaxators) can be presented by their superposition [12, 32]

$$
S_{R \Sigma}=4 \sum_{i=1}^{M} \Delta R_{i}^{2} \cdot \frac{\tau_{\mathrm{ri}}}{\tau_{\mathrm{e} i}+\tau_{\mathrm{c} i}} \cdot \frac{\tau_{\mathrm{r} i}}{1+\left(2 \pi f \tau_{\mathrm{ri}}\right)^{2}}
$$

where $\Delta R_{i}$ is the resistance change of the sample due to electron capture by the localized capture center $i$, $\tau_{\mathrm{ei}}$ is the average electron emission time, $\tau_{\mathrm{ci}}$ is the average electron capture time in the $i$ th defect, and $\tau_{\mathrm{ri}}$ is the effective average relaxation time:

$$
\frac{1}{\tau_{\mathrm{r} i}}=\frac{1}{\tau_{\mathrm{e} i}}+\frac{1}{\tau_{\mathrm{c} i}} .
$$

In Ref. [35], the minimum number of relaxators (defects) has been estimated with relaxation times distributed in a wide time range needed for the generation of noise with the $1 / f$ spectrum. It has been shown that this requirement is fulfilled when the relaxation times are arbitrarily distributed one-by-one in every two-octave range. For example, for the formation of $1 / f$ noise in the frequency range from $1 \mathrm{~Hz}$ to $1 \mathrm{MHz}$ only 15 capture states are needed. In order to obtain the $1 / f$ law in the given frequency range including the end points of that frequency range with high precision, the deviation from $1 / f$ law must be smaller than 5\%: it is a usual accuracy requirement for low-frequency noise measurements. Thus, about two double octave overlaps both to lower and higher frequencies are additionally needed for the simulated frequency range. In this case the noise spectrum is presented by the function $g(f)$ for $K=1$ (Fig. 1, a line with open dots). It is seen that this curve coincides with $g_{0}(f)=0.16 / f$ for the relaxation times distributed uniformly in the logarithmic scale: $\tau_{r i}=\tau_{0} / 4^{i}$. More detailed evaluations show that the factor 0.2 in Eq. (11) in Ref. [35] must be changed to the factor 0.16 . The curve $g(\tau)$ for $K=1$ has only small waves or bumps compared with $g_{0}(f)$. So, the function $g_{0}(f)=0.16 / f$ can be used as a reference one for evaluating Eq. (5) for a different number of defects generating the low-frequency noise.

Factor 0.16 also shows that in the case of change $\Delta N=1$ the maximum value of variance is

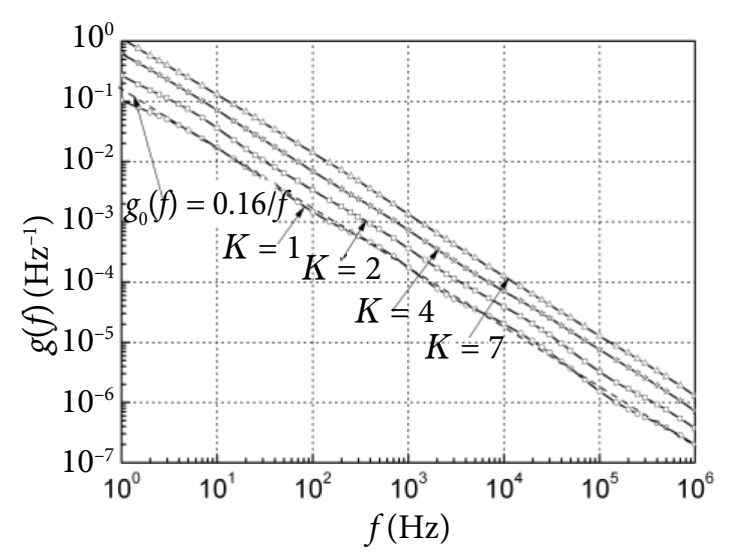

Fig. 1. Modelled low-frequency noise spectra with a small number of widely distributed relaxation times $\tau_{\mathrm{ri}}$. Function $g_{0}(f)=0.16 / f$ (a linear dashed line in the logarithmic scale) shows the $1 / f$ noise spectrum when the relaxation times are distributed as $\tau_{r i}=\tau_{0} / 4^{i}$, i. e. one-by-one in every double octave; other $g(f)$ lines represent the noise spectrum when the number $K$ of relaxators is arbitrarily distributed in the range of every double octave.

$\left\langle(\Delta N)^{2}\right\rangle=1 / 4$ [20]. When in every two-octave range there are $K$ arbitrarily distributed independent relaxators, then $g(\tau)=0.16 \mathrm{~K} / f$ with very small deviations from the 1/flaw (Fig. 11). As pointed in Ref. [35], 
the quantity $K$, but not the total number of defects, must be used for the evaluation of the low-frequency noise level at the defined frequency. For example, the total number of defects in the sample responsible for the $1 / f$ noise in the frequency range from $f_{1}$ to $f_{2}$ can be expressed as $N_{\text {tr }}=K \lg \left(f_{2} / f_{1}\right) / \lg 4$, where the ratio $\lg \left(f_{2} / f_{1}\right) / \lg 4$ corresponds to the number of double octaves in the measured frequency range. In the case when $K$ relaxators are non-uniformly arbitrarily distributed in the $\log \tau$ scale, one will obtain the low-frequency noise spectra with bumps or waves about $1 / f$ law or $1 / f^{\gamma}$ type spectra.

On the ground of this analysis, instead of the characterization of the $1 / f$ noise level in homogeneous materials by the Hooge parameter $\alpha[3,13$, , Palenskis [35] proposed a general expression for the $1 / f$ noise caused by the charge carrier capture-emission process accounting for additional resistance fluctuation because of the Debye screening effect of negatively charged centers due to the electron capture

$$
\frac{S_{R}(f)}{R^{2}}=\frac{\alpha}{N f} \approx \frac{0.16 K \delta}{N} \cdot \frac{1}{N f}
$$

where

$$
\alpha \approx 0.16 K \delta / N,
$$

$K$ is the average number of relaxators in the sample with arbitrarily distributed relaxation times in every double octave, and $\delta$ is the factor accounting for additional resistance fluctuation due to the Debye screening effect; for $\mathrm{Si}$ it can be approximated as $\delta \approx\left(1.3+6.5 \cdot 10^{17} / n\right)^{0.65}$ (here $n$ in $\mathrm{cm}^{-3}$ ) when the defects are localized in the volume of the sample [35]. In the case when defects are localized on the surface of the sample, number 6.5 in the expression for $\delta$ must be decreased by 2 times. When defects are localized in the surface oxide layer, then $\delta \approx 1$. From this study it also follows that the noise correlation length is very small, i. e. of the order of Debye screening length, which is in agreement with the correlation length evaluation (smaller than $1 \mu \mathrm{m}$ ) obtained by Kleinpenning [29].

The relation between the mobility and charge density for $\mathrm{Si}$ in the charge carrier density $n$ range from $10^{15}$ to $10^{19} \mathrm{~cm}^{-3}$ can be approximated as [33, 36 .

$$
\mu=92+1268 /\left[1+\left(n / 1.3 \cdot 10^{17}\right)^{0.91}\right] .
$$

This relation in the range of charge carrier density between $5 \cdot 10^{17}$ to $2 \cdot 10^{18} \mathrm{~cm}^{-3}$ approximately gives the proportionality $\mu^{2} \sim 1 / n$ and $\alpha \sim \mu^{2}$. In other charge carrier density ranges the experimental parameter $\alpha$ values are very scattered [5, 6 ] considering that the spectral density of noise is proportional to $1 / N^{2}$. Thus, the proportionality of the $1 / f$ noise level to squared mobility appears as a presentation effect. Expressions analogous to Eq. (9) can also be written for $\mathrm{Ge}, \mathrm{GaAs}$ and other homogenous semiconductors.

From Eq. (7) it is seen that the $1 / f$ noise level at the constant defect density is proportional to $1 / N^{2}$. Usually the experimental testing of $1 / f$ noise level dependence on the total free charge carrier number $N$ in the sample is being carried out by changing the volume of the sample. In homogeneous samples the ratio $K / N$ with volume increasing is almost constant: it gives an impression that the $1 / f$ noise level is proportional to $1 / N$. Thus, Eq. (7) explains not only the $1 / f$ noise level dependence on frequency but also its dependence both on the number of the free charge carriers and on the number of capture centers, and the observed proportionality to $\mu_{\text {meas }}^{2}$ in a particular range of the charge carrier density $1 / n \sim \mu^{2}$.

In Table 1 , we compared the $1 / f$ noise description parameters (when relaxators are localized in the volume of the sample) in the frequency range between $1 \mathrm{~Hz}$ and $1 \mathrm{MHz}$ for the silicon sample $10 \mu \mathrm{m} \times 10 \mu \mathrm{m} \times 10 \mu \mathrm{m}=10^{-9} \mathrm{~cm}^{-3}$ with the free charge density $n=10^{17} \mathrm{~cm}^{-3}: N=10^{8}$, and the number of $\mathrm{Si}$ atoms $N_{\mathrm{A}}=5 \cdot 10^{13}$ in the sample (density $\left.n_{\mathrm{A}}=5 \cdot 10^{22} \mathrm{~cm}^{-3}\right)$. Here $N_{\mathrm{tr}}$ is the total number of relaxators with arbitrarily distributed $K$ relaxators in every double octave in the given frequency range. It is seen that for $\alpha=10^{-3}$ averagely one capture center (relaxator) is sufficient for $N_{\mathrm{A}}=2.03 \cdot 10^{7}$ atoms of the sample material, and for $\alpha=10^{-5}$ only one relaxator is sufficient for $N_{\mathrm{A}}=2.03 \cdot 10^{9}$. These data visibly demonstrate how the technology of sample formation must be high in order to obtain samples with small values of the parameter $\alpha$.

In order to generate $1 / f$ noise in the frequency range from $1 \mathrm{~Hz}$ to $1 \mathrm{MHz}$, the relaxation times must be arbitrarily distributed in the time interval from $0.01 \mu$ s to $4 \mathrm{~s}$.

Table 1. Relation between the parameter $\alpha$ and low-frequency noise description quantities for Si.

\begin{tabular}{cccc}
\hline$\alpha$ & $10^{-3}$ & $10^{-4}$ & $10^{-5}$ \\
\hline$\delta$ & 3.8 & 3.8 & 3.8 \\
\hline$K$ & $1.64 \cdot 10^{5}$ & $1.64 \cdot 10^{4}$ & $1.64 \cdot 10^{3}$ \\
\hline$N_{\operatorname{tr}}$ & $2.46 \cdot 10^{6}$ & $2.46 \cdot 10^{5}$ & $2.46 \cdot 10^{4}$ \\
\hline$N_{\mathrm{A}} / N_{\operatorname{tr}}$ & $2.03 \cdot 10^{7}$ & $2.03 \cdot 10^{8}$ & $2.03 \cdot 10^{9}$ \\
\hline$N / N_{\text {tr }}$ & 41 & 410 & 4100 \\
\hline
\end{tabular}

Considering that there is some doubt on the possibility of relaxation time distribution in a very wide time range, let us see what values of relaxation times 
can be observed in real samples. The average charge carrier capture time in homogeneous semiconductors is usually determined by relation [12, 37]

$$
\tau=\left(n v_{T} \sigma_{s}\right)^{-1}
$$

where $v_{T}$ is the average thermal velocity of free charge carriers at temperature $T, n$ is the density of free charge carriers, and $\sigma_{\mathrm{s}}$ is the charge carrier scattering crosssection. The effective charge carrier capture cross-sections [31] evaluated on the basis of Eq. (10) for a high purity $p S i$ crystal sample with a very weak shallow doping $\left(p=6 \cdot 10^{11} \mathrm{~cm}^{-3}\right)$ are presented in Fig. 2. It is seen that in many cases the obtained values are by many orders smaller than the cross-section of atoms. According to [12], the states characterized by cross-section values less than $10^{-16} \mathrm{~cm}^{2}$ are related with defect states located in the interfaces and the oxide layer.

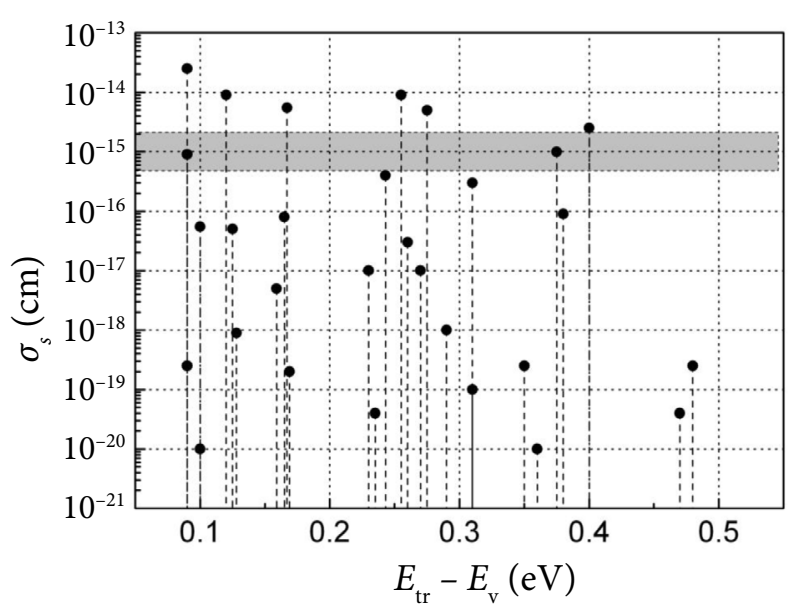

Fig. 2. Charge carrier capture cross-section $\sigma_{\mathrm{s}}$ distribution in the energy gap over the valence band in a high purity $p \mathrm{Si}$ crystal. (The shaded region approximately coincides with the values of the cross-sections of atoms. The plotted cross-section data are taken from Ref. [31]. Here $E_{\mathrm{tr}}$ is the charge carrier trap energy in the energy gap over the valence band top energy $E_{\mathrm{v}}$ ).

A distortion of the band energy can be due to the formation of edge and screw dislocations in the sample [38, 39]. The dislocations attract various impurities, and below the potential barrier there can be many different capture states which are characterized by relaxation times from $10 \mu \mathrm{s}$ to $1 \mathrm{~s}$ [40]. In semiconductors with defect states in surfaces and interfaces the effective charge carrier capture time is presented as

$$
\tau=\left(n v_{T} \sigma_{s}\right)^{-1} \exp \left(\varphi_{\mathrm{B}} / k T\right)
$$

where $\varphi_{\mathrm{B}}$ is the potential barrier height for the distorted potential in the region caused by defect states (Fig. 3).

Usually the exponent in Eq. (11) is assigned to the capture cross-sections:

$$
\sigma_{\mathrm{s}}=\sigma_{\mathrm{s} 0} / \exp \left(\varphi_{\mathrm{B}} / k T\right) .
$$

In order to explain the results of the capture crosssections presented in Fig. 2, the potential barrier height (Fig. 3) must be in the range from 0 to $0.35 \mathrm{eV}$. For the charge carriers to take part in the trapping process in the defect region, their energy must be higher than $E_{\mathrm{G}}+\varphi_{\mathrm{B}}$. So, the effective density of charge carriers (Fig. 3), which can take part in the trapping process, is

$$
n_{\mathrm{eff}} \approx n \exp \left(-\varphi_{\mathrm{B}} / k T\right)
$$

Thus, the relaxation time is very large not due to very small capture cross-sections, but because the effective density of charge carriers $n_{\text {eff }}$ which can take part in the trapping process in the defect region, is smaller than the density $n$ obtained from the Hall measurements.

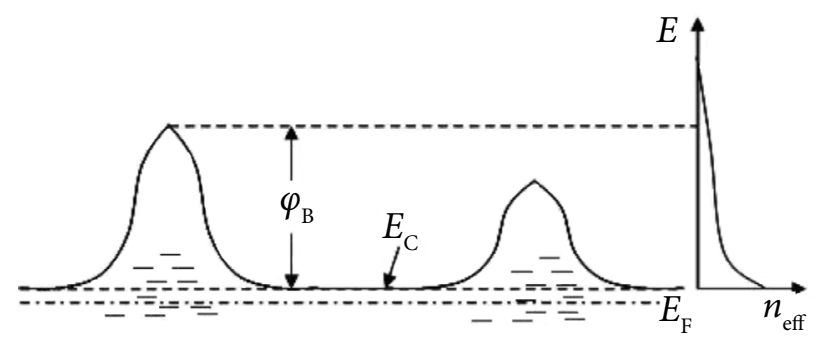

Fig. 3. Schematic large scale distortion of the energy gap due to various relict and formation defects, and the effective free charge carrier density $n_{\text {eff }}$ dependence on energy for a non-degenerate semiconductor.

\section{Summary}

An analysis of the physical mechanisms of the lowfrequency noise in homogeneous materials gives an impression of the proportionality of the resistance fluctuation spectral density to the inverse number of free charge carriers, which can be explained only as an inverse proportionality to the sample volume because the ratio $K / N$ hardly depends on the volume for homogeneous material. The minimum number of defects generating the $1 / f$ noise law in a particular frequency range does not depend on the volume of the sample: the volume only determines the intensity of the $1 / f$ noise. When some type of relaxators with 
particular relaxation times by many times exceeds the average number of relaxators with other relaxation times, one can observe the Lorentzian type spectrum over the $1 / f$ noise. The present analysis shows that the charge carrier capture and emission process is the main source for the $1 / f$ noise and the RTS noise. The proportionality of the $1 / f$ noise level to squared mobility in a particular charge carrier density range cannot be interpreted as mobility fluctuations, because it appears as the effect of noise level presentation on mobility. Mobility fluctuations can in some cases appear as a secondary effect. Eqs. (5) and (7) explain the formation of the $1 / f$ type noise spectrum and its level dependence on both the number of defects and the number of free charge carriers in the sample.

\section{References}

[1] J.H.J. Lorteije and A.M.H. Hoppenbrouwers, Amplitude modulation by $1 / f$ noise in resistors results in $1 / \Delta f$ noise, Philips Res. Repts. 26, 29-39 (1971).

[2] B.K. Jones and J. Francis, Direct correlation between $1 / f$ and other noise sources, J. Phys. D 8, 1172-1176 (1975).

[3] V.P. Palenskis, G.E. Leont'ev, and H.S. Mykolaitis, On the origin of the $1 / f$ noise in linear resistors and p- $n$ junctions, Radiotekh. Elektron. 21, 2433-2434 (1976) [In Russian, Radio Eng. Electron. Phys.].

[4] R.F Voss and J. Clarke, $1 / f$ noise from systems in thermal equilibrium, Phys. Rev. Lett. 36, 42-45 (1976).

[5] F.N. Hooge, Discussion of recent experiment on 1/f noise, Physica 60, 130-144 (1972).

[6] F.H. Hooge, T.G.M. Kleinpenning, and L.K.J. Vandamme, Experimental studies on $1 / f$ noise, Rep. Progr. Phys. 44, 479-532 (1981).

[7] P. Dutta and P.M. Horn, Low-frequency fluctuations in solids: $1 / f$ noise, Rev. Mod. Phys. 53, 497516 (1981).

[8] B. Pelegrini, One model of flicker, burst, and generation-recombination noises, Phys. Rev. B 24, $7071-7083$ (1981).

[9] A. Van der Ziel, A Noise in Solid State Devices and Circuits (Wiley-Interscience Publications, John Wiley \& Sons, New York, 1986).

[10]A.L. McWhorter, in: Semiconductor Surface Physics, ed. R.H. Kingstone (University of Pensylvania Press, 1957) pp. 207-228.

[11] M.B. Weissman, $1 / f$ noise and other slow, nonexponential kinetics in condensed matter, Rev. Mod. Phys. 60, 537-571 (1988).

[12] M.J. Kirton and M.J. Uren, Noise in solid-state microstructures: A new perspective on individual defects, interface states and low-frequency $(1 / f)$ noise, Adv. Phys. 38, 367-468 (1989).
[13] V. Palenskis, Flicker noise problem (review), Lith. J. Phys. 30, 107-152 (1990).

[14] B.K. Jones, Electrical noise as a measure of quality and reliability in electronic devices, in: Advances in Electronics and Electron Physics, Vol. 87 (Elsevier, 1993) pp. 201-257.

[15] F.N. Hooge, $1 / f$ noise sources, IEEE Trans. Electron Dev. 41, 1926-1935 (1994).

[16]M.S. Kogan, Electronic Noise and Fluctuations in Solids (Cambridge University Press, New York, 1996).

[17] B. Pelegrini, A general model of $1 / f^{\prime}$ noise, Microelectron. Reliab. 40, 1775-1780 (2000).

[18] M. Nardone, V. Kozub, I.V. Karpov, and V.G. Karpov, Possible mechanisms for $1 / f$ noise in chalcogenide glasses: A theoretical description, Phys Rev. B 79(16), 165206 (2009).

[19] M.J. Uren, D.J. Day, and M.J. Kirton, $1 / f$ and random telegraph noise in silicon metal-oxide-semiconductor field-effect transistors, Appl. Phys. Lett. 47, 1195-1197 (1985).

[20] L.K.J. Vandamme and F.H. Hooge, What do we certainly know about $1 / f$ noise in MOSTs? IEEE Trans. El. Dev. 55, 3070-3085 (2008).

[21]F.H. Hooge and L.K.J. Vandamme, Lattice scattering causes $1 / f$ noise, Phys. Lett. 66A, 315-316 (1978).

[22]F.H. Hooge, in: Proceedings of the 7th Vilnius Conference on Fluctuation Phenomena in Physical Systems, ed. V. Palenskis (VU Press, Vilnius, 1994) pp. 61-69.

[23] F.H. Hooge, in: Proceedings of the 13th International Conference on Noise in Physical Systems and $1 / f$ Fluctuations, eds. V. Bareikis and R. Katilius (World Scientific, Singapore, 1995) pp. 8-13.

[24]T.G.M. Kleinpenning, $1 / f$ noise in Hall effect: Fluctuations in mobility, J. Appl. Phys. 51, 3438 (1980).

[25] R.P. Jindal and A. Van der Ziel, Phonon fluctuation model for flicker noise in elemental semiconductors, J. Appl. Phys. 52, 2884-2888 (1981).

[26] S.V. Melkonyan, V.M. Aroutiounian, F.V. Gasparyan, and H.V. Asriyan, Phonon mechanism of mobility equilibrium fluctuations and properties of $1 / f$ noise, Phys. Rev. B 382, 65-70 (2006).

[27] B.C. Daly, K. Kang, Y. Wang, and D.G. Cahill, Picosecond ultrasonic measurements of attenuation of longitudinal acoustic phonons in silicon, Phys. Rev. B 80, 1744112 (2009).

[28]J. Cuffe, O. Ristow, E. Chávez, A. Shchepetov, P.-O. Chapuis, F. Alzina, M. Hettich, M. Prunnila, J. Ahopelto, T. Dekorsy, and C.M. Sotomayor Torres, Lifetimes of confined acoustic phonons in ultrathin silicon membranes, Phys. Rev. Lett. 110, 095503 (2013).

[29] T.G.M. Kleinpenning, Theory of noise investigations on conductors with four-probe method, J. Appl. Phys. 48, 2946-2949 (1977). 
[30]Z. Šoblickas and V. Palenskis, Noise spectroscopy of impurity levels and $1 / f$ noise in high resistance silicon, Lith. J. Phys. 25, 88-97 (1985).

[31] V. Palenskis, K. Maknys, A. Stadalnikas, Z. Šoblickas, and A. Utorovičius, in: Proceedings of the 7th International Vilnius Conference on Fluctuation Phenomena in Physical Systems, ed. V. Palenskis (VU Press, Vilnius, 1994) pp. 266273.

[32] S. Machlup, Noise in semiconductor: spectrum of two parameter random signal, J. Appl. Phys. 25, 341-343 (1954).

[33]C. Jacoboni, C. Canali, G. Ottaviani, and A. Alberigi Quaranta, A review of some charge transport properties of silicon, Solid State Electron. 20, 77-89 (1977).

[34] V. Palenskis, Transport of electrons in donordoped silicon at any degree of degeneracy of electron gas, World J. Condens. Matt. Phys. 4, 123-133 (2014).
[35] V. Palenskis and K. Maknys, Nature of low-frequency noise in homogeneous semiconductors, Sci. Rept. 5, 18305 (2015).

[36] A. Dargys and J. Kundrotas, Handbook on Physical Properties of Ge, Si, GaAs and InP (Science and Encyclopedia Publishers, Vilnius, 1994).

[37] J. Pavelka, J. Šikula, M. Chvatal, and M. Tacano, in: Proceedings of the 2015 International Conference on Noise and Fluctuations ICNF 2015 (IEEE, 2015) pp. 349-352.

[38] H.F. Mataré, Defect Electronics in Semiconductors (John Wiley and Sons, Inc., New York, 1971).

[39] K.V. Ravi, Imperfections and Impurities in Semiconductor Silicon (John Wiley and Sons, Inc., New York, 1981).

[40] R.H. Galenzer and A.G. Jordan, The electrical properties of dislocations in silicon - I: The effects on carrier lifetime, Solid State Electron. 12, 247258 (1969).

\title{
KRŪVININKŲ PAGAVIMAS IR JŲ IŠLAISVINIMAS - PAGRINDINIS VIENALYČIŲ PUSLAIDININKIŲ ŽEMADAŽNIO TRIUKŠMO ŠALTINIS
}

\author{
V. Palenskis \\ Nacionalinis fiziniu ir technologijos mokslu centras, Vilniaus universiteto Fizikos fakultetas, Vilnius, Lietuva
}

\begin{abstract}
Santrauka
Atlikta detali homogeninių medžiagų žemadažnio $(1 / f)$ triukšmo analizè parodè, kad tiriamojo bandinio varžos fliuktuacijų spektrinio tankio atvirkštinis proporcingumas laisvųjų krūvininkų skaičiui bandinyje gali būti vertinamas tik kaip atvirkštinis proporcingumas bandinio tūriui. Matavimo ir skaičiavimo rezultatai rodo, kad žemadažnio triukšmo spektras vienareikšmiškai gali būti išreikštas Lorenco pavidalo spektrais, iskaitant atsitiktinai pasiskirsčiusias relaksacijų trukmes labai plačiame intervale.
\end{abstract}

Ivvertintas mažiausias relaksatorių skaičius, galintis sukurti $1 / f$ pavidalo triukšmo spektrą tam tikrame dažnių intervale. Parodyta, kad krūvininkų judrio fliuktuacijos gali pasireikšti tik kaip antrinis reiškinys, atsirandantis defektuose kintant sklaidos centrų skaičiui dèl krūvininkų pagavimo ir jų išlaisvinimo iš lokalizuotų centrų. Pateikta kiekybinè išraiška, leidžianti pagal išmatuotą žemadažnị triukšmą tam tikrame dažnių intervale ịvertinti aktyviu pagavimo centrų skaičių bandinyje, lemiantį išmatuotą triukšmą. 